\title{
REVISÃO BIBLIOGRÁFICA SOBRE A MANUFATURA ÁGIL E COMPARAÇÃO E DIFERENCIAÇÃO ENTRE TRÊS ERAS PRODUTIVAS
}

\section{BIBLIOGRAPHICAL REVISION ON THE AGILE MANUFACTURE AND COMPARISON AND DIFFERENTIATION BETWEEN THREE PRODUCTIVE AGES}

\section{Guilherme José de Mattos Barreto, M.Sc.}

Mestrado Profissional em Sistemas de Gestão/Laboratório de Tecnologia, Gestão de Negócios e Meio Ambiente/UFF - Rua Passo da Pátria, 156/329-A, 24210-240-Niterói-RJ (21) 27176390 - guilherme@latec.uff.br

José Rodrigues de Farias Filho, D.Sc.

Mestrado Profissional em Sistemas de Gestão/Laboratório de Tecnologia, Gestão de Negócios e Meio Ambiente/UFF - Rua Passo da Pátria, 156/329-A, 24210-240-Niterói-RJ (21) 27176390 - rodrigues@civil.uff.br

\section{Christian Augusto Guimarães Vargas Carneiro, M.Sc.}

Mestrado Profissional em Sistemas de Gestão/Laboratório de Tecnologia, Gestão de Negócios e Meio Ambiente/UFF - Rua Passo da Pátria, 156/329-A, 24210-240-Niterói-RJ (21) 27176390 - christian@latec.uff.br

Ana Paula Paiva de Farias, Mstd.

Mestranda em Engenharia de Produção - Departamento de Eng. de Produção - LATEC/UFF R. Passo da Pátria, 156/329-A, 24210-240 - Niterói-RJ - cel: 9266-5790 - paula@ latec.uff.br

\section{RESUMO}

As incertezas de mercado decorrentes do atual ambiente de negócios acarretam mudanças. Estas podem ocorrer nas regras que incidem sobre o mercado competitivo, nas empresas que atuam neste mercado ou na mudança de conduta das relações entre estas partes. 
Conseguir transformar estas mudanças em oportunidades de negócios é um dos principais desafios de empresas que pretendem sobreviver e prosperar. E é exatamente neste sentido que o conceito de manufatura ágil tende a se orientar. Este trabalho se processa inicialmente com a revisão bibliográfica sobre aspectos introdutórios relevantes ao tema, dentro do plano amostral cronológico proposto, aborda as características em que se baseia este conceito, histórico e definições importantes. Em um segundo estágio é desenvolvida uma breve diferenciação entre três diferentes eras produtivas: manufatura ágil, produção enxuta e produção em massa. Neste passo a condução do assunto é dada de forma a subentender que as eras industriais são conseqüentes e evolutivas. Por fim, se dá uma comparação lateral entre os métodos gerenciais, ferramentas produtivas e idéias que orientam os três diferentes conceitos.

Palavras-chave: Manufatura ágil, comparação, gerenciamento da produção

\begin{abstract}
Nowadays the market uncertainty and the business environment are important causes of changes. These changes can be realized in the competitive market, at the enterprises that operate on these markets, or at the relation between both. Turn these changes on opportunities is one of the important challenges of enterprises that expect to survive and be well in business. And it is the very idea of the agile manufacturing concept. This paper initially presents a literature review, displaying the introductory characteristics of this concept, the impressive definitions. In a second apprenticeship a superficial differentiation is developed among three different strategies: the agile manufacturing, dry production and mass production. This step is an exposure about the sense of evolution between these eras. Finally, it is proposed a lateral comparison among the managerial methods, productive tools and ideas that guide the three different concepts.
\end{abstract}

Key words: Agile manufacture, comparison, production management

\title{
1 REVISÃO DA LITERATURA
}

O esforço de se promover a revisão bibliográfica da literatura acessível sobre o conceito de manufatura ágil tem o intuito de, em relação aos possíveis leitores deste trabalho, servir como fonte de informações introdutórias críveis e relevantes sobre o assunto, para que possa servir como ponto primeiro no processo de investigação e pesquisa sobre a manufatura ágil. 
Este trabalho de revisão visa a ser uma introdução sobre o conceito de manufatura ágil como tema exploratório. Para tanto, o plano amostral cronológico deste trabalho compreende o intervalo de tempo que começa em 1967, ainda com os pioneiros estudos sobre o gerenciamento da mudança de Thompson (1967) e Drucker (1968), passa pelo final da década de 90, onde foram propostas as primeiras ponderações sobre métodos de avaliação da agilidade, tais como as de Irani, Sharp e Desai (1999), e termina em 2001, quando finda no livro lançado por Gunasekaran (2001) elevando a importância da manufatura ágil ao patamar de "o conceito do século 21".

Os itens da revisão bibliográfica são dispostos desta forma porque seguem um formato a que o pesquisador considera mais apropriado e de mais fácil entendimento. A concatenação destes não considera nenhum tipo de objetivo senão o de facilitar e racionalizar a leitura.

\subsection{INTRODUÇÃO}

Existe atualmente um reconhecimento mundial de que a manufatura ágil é condição necessária para a competitividade. O conceito original foi popularizado em 1991 por um grupo de pesquisadores do Iaccoca Institute of Lehigh University (Iaccoca Institute, 1991) nos EUA, como sendo o novo campo de batalha para a competitividade global, em face ao encolhimento dos mercados convencionais e das decorrentes novas barreiras.

Atualmente, ainda não se tem notícia de alguma empresa brasileira que seja verdadeiramente ágil, no sentido de ter conseguido alcançar todas as características essenciais da literatura até então acessível sobre agilidade. Existem vários assuntos e questões que devem ser respondidos para o real entendimento e a consolidação do tema, tais como assegurar com certeza o propósito, o foco estratégico e as melhorias conseqüentes do processo, entre outras. No decorrer deste processo de revisão estaremos abordando estes assuntos, com o intuito de auxiliar no desenvolvimento do conceito.

\subsubsection{O paradigma do século 21}

Agilidade como conceito de manufatura foi introduzida por um grupo de pesquisadores do Iaccoca Institute of Lehigh University, (Iaccoca Institute, 1991) em 1991 para descrever as práticas observadas e consideradas como aspectos importantes de manufatura, durante a investigação. O grupo era constituído por executivos sêniores de várias companhias americanas. O estudo culminou em um documento de dois volumes que 
salientava uma nova visão direcional da indústria, que possibilitaria profundas mudanças no paradigma da manufatura.

O estudo tratava principalmente sobre como os Estados Unidos alcançariam novamente a liderança mundial em manufatura, e descrevia iniciativas dos Estados Unidos, da Europa Ocidental e do Japão que visavam a criar um clima industrial que possibilitaria o aumento da competitividade na nova ordem global de manufaturas. O paradigma da manufatura ágil foi recomendado como sendo o potencializador dessa situação, caso fosse realmente adotado, de retomada de liderança do campo da manufatura. Neste tratado tem especificado uma visão de como uma empresa ágil deveria ser, sua infra-estrutura e operações. Também foram propostas relações sobre competitividade ágil, subsistemas e elementos habilitadores da agilidade. O estudo foi o trabalho pioneiro e como tal, aceito por acadêmicos, executivos e órgãos governamentais.

Contudo, Burgess (1994) constatou que a definição fruto deste processo era genérica, e que mais esforços nesse sentido seriam necessários para refinar e estruturar o conceito, principalmente na diferenciação de especificações.

\subsubsection{A experiência acadêmica}

Desde a década de 80 até os dias atuais, vários estudos foram desenvolvidos no sentido de entender as raízes e causas das novas ordenações no mercado mundial, seguindo as mudanças políticas e econômicas mundiais. Universidades de todo o mundo e fundações de pesquisa ainda se esmeraram nessa tarefa.

O estudo de Clark e Fujimoto (1991) desenvolveu um acompanhamento de cinco anos sobre o assunto: Processo Mundial de Desenvolvimento de Produto. O resultado foi a caracterização de novas forças que conduzem ao novo ambiente de negócios mundial, que são: a emergente e intensa competitividade mundial, a criação de mercados fragmentados conduzidos pela demanda, sofisticação dos clientes e a diversidade de mudanças no campo da tecnologia de transformação. Estudos como este têm conseguido suporte direto de vários pesquisadores que trabalham com o tema da mudança e metodologias de convivência com o caos e incertezas.

Segundo Davis (1995), o maior problema de um executivo atualmente é a dificuldade de gerenciamento da mudança - responder às mudanças externas de mercado e gerenciar as mudanças internas produtivas e gerenciais decorrentes. 
Pela grande gama de áreas de pesquisa, como também pela diversidade de enfoques dados a cada assunto estudado, a postulação de como uma organização chegaria ao sucesso empresarial dificilmente se daria de forma unânime, posto que muitas vezes as opiniões de diferentes estudiosos divergem entre si. Certo é dizer que alguns fatores facilitam este processo, como por exemplo: ênfases em novas prioridades de negócios como redução dos desperdícios de tempo e flexibilidade, métodos, ferramentas e técnicas de melhoria de processo produtivo e administrativo, utilização de sistemas de informação/tecnologia e facilidades de tráfego de dados, integração de todo o processo produtivo, incremento nas inovações em toda a organização, cooperação e organização virtual, produção baseada na customização do cliente, etc.

\subsubsection{Generalidades}

A principal força condutora da agilidade é a mudança. A manufatura deve estar preparada para incorrer em mudanças que visem responder às circunstâncias impostas pelo mercado. Mudanças e incertezas no ambiente de negócios são alvo de pesquisas e estudos gerenciais há muitos anos.

Thompson (1967) escreveu que uma das mais importantes tarefas das organizações é gerenciar as incertezas. Segundo Drucker (1968) a organização deve estabelecer a seguinte ordem a esta tarefa: procurar por mudanças, respondê-las e explorá-las como uma oportunidade. Como Hayen (1988) acredita, não existe nada novo sobre as mudanças.

Tempos de turbulência e incertezas no ambiente de negócios são apontados como causas de fracassos de empresas desde sempre. Mudanças rápidas e dramáticas na tecnologia, principalmente no campo de ele trônicos, foram o centro nervoso nas décadas de 60 e 70, que se estenderam nas últimas duas décadas, para outros aspectos e áreas da economia. Estes aspectos incluem mercado, competição, necessidade dos clientes, fatores sociais, etc., que por sua vez passaram a acarretar mais e mais mudanças. O que se constata é que estas mudanças resultantes de freqüentes evoluções dos sistemas de negócios e a conseqüente criação de novas filosofias gerenciais e de manufatura relacionadas a elas parecem estar muito mais suscetíveis e serem muito mais inesperadas atualmente do que em qualquer outro momento da história. 


\subsubsection{O ambiente de negócios e a evolução do mercado}

Os negócios estão se reestruturando e entrando em um processo de reengenharia numa tentativa de responder aos desafios e demandas do século 21. Segundo Bunce e Gold (1996), os negócios do século 21 deverão subjugar estes desafios de demanda dos clientes empenhando alta qualidade, produtos a custos mais baixos, ter alto poder de resposta para suas específicas e para as rápidas mudanças de demanda.

Agilidade orienta o novo esforço das empresas em vencer estes desafios. Segue um sucinto demonstrativo das principais funções que orientaram as evoluções estratégicas, gerenciais e filosóficas das eras produtivas ao longo do século vinte.

\section{A) Automação e consideração de preço/custo}

Segundo Plossl (1997) as pressões que incidem sobre a economia sempre foram ditadas pelo mercado. O pós II Guerra Mundial foi caracterizado por uma relativa alta demanda e pela incapacidade de supri-la. Qualidade ou velocidade de entrega não tinham grande importância no que se referia à demanda dos clientes. Preço era o fator dominante para a preferência de determinado produto. Esta situação encorajava as grandes empresas de manufatura à automação maciça dos processos produtivos. $\mathrm{O}$ principal objetivo das manufaturas era a maciça produção a preços mais baixos. A automação era rígida e a flexibilidade inexistente.

B) Ampliando as opções e expectativas dos clientes

A mudança de mercado e a evolução da preferência dos clientes em favor da qualidade se deram apenas na década de 80. Este fato orientou um novo foco, agressivo e sem precedentes, na busca pela qualidade, enquanto ainda se tentava manter os preços competitivos. Aumentar a expectativa do cliente sob o ponto de vista da qualidade ajudou a intensificar a atenção dada às iniciativas de produção com qualidade. A revolução engendrada pelos executivos de manufaturas foi também complementada pelo exército de pesquisadores e consultores que popularizaram os conceitos relativos e acessíveis à qualidade, como Gerenciamento pela Qualidade Total (TQM), Controle por Processo Estatístico (SPC), BS 8800 e ISO 9000 e 14000, entre vários outros. 


\section{C) Prioridades competitivas}

Segundo Gerhani (1995) vários critérios de competitividade hoje amplamente discutidos emergiram na primeira metade de 1990. Estas prioridades competitivas incluem poder de resposta, introdução de novos produtos, entrega em casa, flexibilidade, qualidade e a preocupação com o ambiente e com a competitividade mundial. $\mathrm{O}$ mercado se tornou um verdadeiro campo de batalha. Exemplo disso foi a verdadeira luta travada entre a Honda e Yamaha pela participação no mercado, nos idos de 80.

Para a formulação da estratégia de economia de escalas passou a se levar em conta vários novos fatores, tendendo a se converter em uma nova visão de economia de competência, de oportunidades.

\section{D) Integração e pró-atividade}

Para Lindberg (1990) o paradigma de manufatura estabelecido tem uma concepção amplamente reativa. Em um mercado altamente competitivo as manufaturas devem ser capazes de agir pró-ativamente. Uma manufatura pró-ativa irá integrar-se com os clientes e ajudar a definir seus problemas e demandas. Neste sentido, a pró-atividade oferece vantagem competitiva em um turbulento mercado global. As capacidades estratégicas fornecidas pela pró-atividade são fortemente dependentes da integração e coordenação da empresa.

E) Obtendo a sinergia dos requerimentos de manufatura

Vários conceitos devem funcionar ao mesmo tempo para que o processo de evolução gerencial tenha êxito. De pouco adianta a excelência em apenas um quesito. A importância da velocidade, por exemplo, não pode ser superestimada. A flexibilidade da produção, bem como os funcionários e a organização são requisitos básicos para uma estratégia corporativa flexível. Para se fomentar a competitividade, manufaturas devem produzir a preços baixos, alta qualidade e decréscimo de tempos principais. Além de trabalhar pró-ativamente e inovando sempre.

Uma empresa que almeja o sucesso deve então conseguir a capacidade de obter e explorar a vantagem competitiva em sinergia. Integração dos campos de natureza tecnológica ou social, tecnologia dos equipamentos, maquinaria, funções, estratégias, pessoal e gerenciamento.

Portanto, para Goldman e Nagel (1993) empresas com sucesso devem ter habilidades como alto poder de previsão, de adaptação e de resposta às mudanças. Sobreviventes são 
aquelas que adquirirem a proficiência da mudança e a utilizam como vantagem competitiva, na possibilidade de transformação destas mudanças em oportunidades para elas próprias.

\title{
1.2 DEFINIÇÕES DE AGILIDADE
}

Os autores do trabalho da Iaccoca Institute of Lehigh University (Iaccoca Institute, 1991) definiram agilidade como:

\begin{abstract}
Um sistema de manufatura com capacidades extraordinárias (capacidades internas: tecnologias de hardware e software, recursos humanos, gerenciamento específico e informação) para acompanhar as rápidas mudanças de necessidade de mercado (velocidade, flexibilidade, clientes, competidores, fornecedores, infra-estrutura, poder de resposta). Um sistema que muda rapidamente (velocidade e poder de resposta) de modelos de produtos ou de linhas de produção (flexibilidade), consegue responder à demanda do cliente (necessidades e desejos dos clientes).
\end{abstract}

Esta definição baseia os conceitos refletidos pelo modelo de manufatura ágil proposto por Youssef (1992). O modelo define uma estrutura para a agilidade através da representação de interações entre a manufatura, os clientes, os fornecedores e a base para competição do paradigma ágil.

Segundo Kidd (1996) manufatura ágil vem sendo definida como a capacidade de sobreviver e prosperar no ambiente competitivo de contínuas e imprevisíveis mudanças, pela reação rápida e efetiva às mudanças de mercado, conduzidas pela busca de produtos e serviços projetados para o cliente. A manufatura ágil pode baixar os custos de manufatura, aumentar a fatia de mercado, satisfazer aos requisitos dos clientes, facilitar a introdução de novos produtos, eliminar as atividades que não agregam valor e aumentar a competitividade da manufatura.

Agilidade é sobre abandonar os antigos processos de se fazer as coisas, que hoje soam obsoletos. JamesMoore (1996) e Gould (1997) preconizam em seus respectivos trabalhos que se deve trocar os modelos tradicionais de operação. Em um ambiente competitivo e intensamente instável, é necessário desenvolver organizações e facilidades substancialmente mais flexíveis e com maior poder de resposta do que as que hoje existem. 
O professor e pesquisador Zahir Irani (1999) mostrou que estão incluídos na Manufatura Ágil os conceitos de realização rápida do produto, manufaturas de alta flexibilidade e integração da empresa. Tecnologia sozinha não torna uma empresa ágil. A empresa deve encontrar a combinação certa entre a sua cultura organizacional e as boas práticas de excelência.

Gunasekaran (1999) definiu primeiramente manufatura ágil como sendo a capacidade de sobreviver e prosperar em um ambiente competitivo de contínua e imprevisível mudança, reagindo rapidamente e efetivamente às mudanças de mercado. Mais adiante será abordada a sua definição compreensiva, tida como mestra para este trabalho.

Para Baker (1996), manufatura ágil é uma nova expressão que representa o produtor de bens e serviços que trabalha sempre encarando contínuas mudanças. Estas mudanças são suscetíveis de acontecer em mercados, em tecnologias, em relações de negócios ou em qualquer faceta de mercado. A manufatura ágil requer competências únicas, organização e gerenciamento da mudança e incerteza e elevação do nível de pessoal e da informação.

Para Youssef (1992), Brooke(1993) e Baker (1996) a agilidade em conceito prevê dois fatores principais: capacidade de resposta à mudança (antecipação ao inesperado) de modo saudável e em tempo suficiente e transformação da mudança em oportunidade e conseqüente fonte de obtenção de vantagem competitiva. Estes, por sua vez, necessitam de uma habilidade básica, a sensibilidade, percebendo e antecipando mudanças no ambiente de negócios da empresa.

Manufatura ágil propriamente dita é encontrada em uma empresa que tem uma ampla visão do novo, da nova ordem de negócios mundial, mais o domínio das capacidades e habilidades para lidar com turbulências e antever o melhor lado do negócio.

Youssef (1992) mostra que a agilidade não pode ser alcançada somente com o incremento da velocidade em se fazer os procedimentos propostos, necessitando também de profundas mudanças estruturais e infra-estruturais. Relacionar a definição de manufatura ágil unicamente à velocidade de resposta e flexibilidade constitui uma visão pequena dos incrementos que podem ser alcançados com o conceito. Embora a agilidade tenha incorporado o poder de resposta e a flexibilidade, segundo Kidd (1994) ela é muito mais do que isso, pois existe o lado novo e fortemente estruturado em pesquisa, como também o uso sintetizado de tecnologias e métodos já desenvolvidos e bem conhecidos. Goldman e Nagel (1993) notam que a manufatura ágil assimila todo o leque de tecnologias da produção flexível, aprende lições desde o gerenciamento da qualidade, do JIT até a Lean Production, mais comumente 
conhecida no Brasil como produção enxuta. Mais à frente serão abordados aspectos relevantes para esta dissertação sobre estes conceitos.

Agilidade é a habilidade de um negócio de crescer em um mercado competitivo de contínua e imprevisível mudança, de responder rápida, eficaz e eficientemente a esta mudança, orientada pela demanda do cliente (Kidd, 1996). Enfocando o resultado da produção, Gehani (1995) revela que "uma organização ágil pode rapidamente satisfazer a ordenação do cliente, pode introduzir novos produtos de um modo sistemático e pode ainda entrar ou sair de alianças estratégicas velozmente".

Portanto, para efeito de organização deste trabalho, a definição considerada pelo pesquisador como aquela que mais adequadamente enfoca todos os aspectos definidos foi considerada como a definição compreensiva da agilidade. Esta é assunto do próximo item.

\subsubsection{Definição compreensiva de agilidade}

Obviamente várias facetas da agilidade vêm sendo enumeradas por diferentes pesquisadores do assunto. Com o aumento de literatura sobre agilidade, Gunasekaran, Yusuf e Sarhadi (1999) propuseram uma definição compreensiva. Esta é a definição mestra que ordenará todo este trabalho.

Agilidade é a exploração com sucesso das bases competitivas - velocidade, flexibilidade, pró-atividade, qualidade e lucratividade - através da integração dos recursos reconfigurados - tecnologia, informação e pessoal - e pelas boas práticas - estratégias, métodos e ferramentas gerenciais - em um ambiente rico em conhecimento - energização de pessoal fluxo de sistemas de dados, fornecendo produtos e serviços projetados segundo a demanda do cliente em uma ambiente de mercado de contínua e imprevisível mudança.

Esta definição compartilha algumas propriedades com as demais definições, porém se diferencia em quatro aspectos:

1. É compreensível que a definição seja estruturada em termos de entrada, operacionalização e resultados. Isto sugere o conceito de manufatura ágil como um sistema. É uma visão sistemática que habilitará os praticantes a distinguirem entre os requeridos dados de entrada, o mecanismo de operação e ferramentas, e os resultados esperados; 
2. Os fundamentos competitivos são sugeridos explicitamente claros. A base de competição inclui: velocidade, flexibilidade, inovação, pró-atividade, qualidade e lucratividade. Estes, conforme salientado anteriormente devem ser trabalhados com sinergia, sem rompantes em uma ou outra direção;

3. Existem três níveis de agilidade implícitos na definição. São eles a agilidade individual (e outros recursos), agilidade da empresa e a agilidade interempresas. A figura 1 sugere uma hierarquia da agilidade. Uma verdadeira organização ágil enfoca os recursos individuais (pessoal, equipamento e gerenciamento) e as funções que fazem a empresa a obter o melhor resultado possível. É a harmonização desses aspectos da organização que conduzem à agilidade otimizada. O próximo passo é a delimitação das competências únicas visando a formação de parcerias, visando maximizar os ganhos de cooperação.

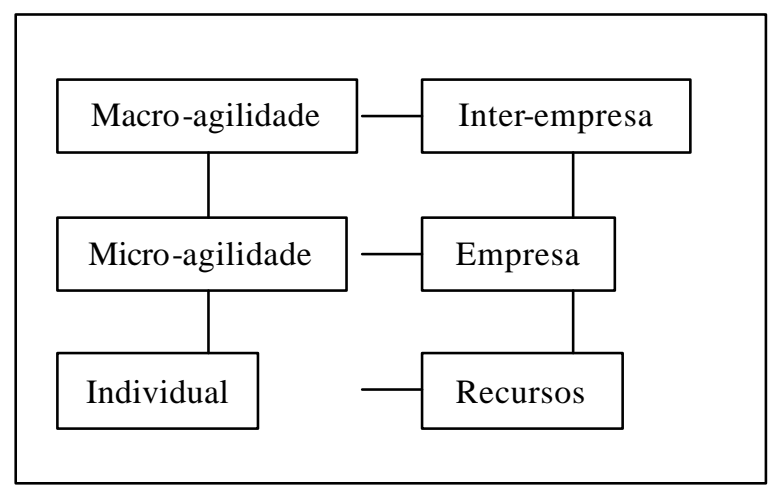

Figura 1 - Hierarquia da agilidade. Gunasekaran, Yusuf e Sarhadi (1999) 


\section{COMPARAÇÃO E DIFERENCIAÇÃO DAS TRÊS ERAS PRODUTIVAS (PRODUÇão EM MASSA, PRODUÇÃo ENXUTA E MANUFATURA ÁGIL) E SUAS INTERAÇÕES}

As mudanças do ambiente de negócios são sempre mais sentidas nas empresas, o que implica na apresentação de um inerente dinamismo de negócios, cujo significado é que a estas é ininterruptamente exigida a melhoria do desempenho no negócio. Empresas estão continuamente lidando com mudanças de mercado cada vez mais imprevisíveis e diversificadas, como a competição globalizada ou as mudanças de demanda dos clientes. Empresas hoje em dia devem ser hábeis a não só prever variações e mudanças no mercado e no ambiente político, econômico e social como também devem ser capazes de se adaptar e mudar diante desta nova demanda.

Como resultado, estas demandas desenvolvem e sustentam na empresa uma habilidade de contínua adequação às mudanças. Esta situação pode ser assegurada se implementando a filosofia gerencial da manufatura ágil. Todavia, por vezes as empresas não têm consciência de quão longe ou perto estão dos conceitos que reguem um sistema de manufatura ágil.

Pensando neste sentido é que Irani, Sharp e Desai (1999) fundamentam um estudo sobre a indústria britânica segundo o novo foco da manufatura ágil, suas interações com a produção enxuta e a produção em massa.

Atualmente, existe uma gama muito grande de estratégias, conceitos e fórmulas de gerenciamento de manufaturas que concorrem ou interagem entre si. Conceitos como a produção enxuta, do Sistema Toyota de Produção, a produção em massa, a World Class, conhecida no Brasil como produção classe mundial, ou até mesmo a manufatura ágil, para não citar inúmeros outros, participam da panacéia conceitual em que atualmente a gerência de manufatura submerge. Entretanto, muitas vezes estes conceitos não têm ao menos uma definição base ou consensual.

A definição de manufatura ágil, entretanto e, particularmente se tratando deste trabalho, foi propositadamente debatida no último item. Ali se tentou achar uma definição que ordenasse e acima de tudo representasse, mesmo que tão somente para esta pesquisa, a melhor, mais objetiva e inteligível definição de todas. E a que se chegou, como já foi mencionado, foi a proposta por Gunasekaran, Yusuf e Sarhadi (1999). 
Por outro lado, existe discordância em torno de como a Manufatura Ágil se deu como conceito. Segundo Sharifi e Zhang (1999), a manufatura ágil foi por vezes misturada e confundida a outros pensamentos acadêmicos de gerenciamento de manufaturas preexistentes, como flexibilidade e manufatura enxuta, mostrando o assunto como uma curta evolução do que já se tinha sido amplamente discutido, tratando a manufatura ágil como uma solução dentro da solução já existente, que trabalharia apenas naqueles focos que as demais tinham sido incapazes. Para eles, a manufatura ágil nasceu de uma nova e independente corrente filosófica.

Porém, para Gunasekaran (1999) a agilidade é estritamente uma visão de manufatura evoluída naturalmente da forma original, o conceito de produção enxuta. Nesta a ênfase é dada no corte de custo, enquanto a facilidade, a flexibilidade e o maior poder de resposta requerido pela manufatura ágil transparece numa forma diferente da antiga. $\mathrm{O}$ requerimento que incide sobre a manufatura ágil de responder às demandas únicas do mercado remete à situação quando a produção enxuta foi introduzida, posto que naquela época a intenção era que esta fosse capaz de responder a quaisquer pressões impostas sobre a empresa, sob o aspecto de riscos de custo e qualidade.

Quem participa desta afirmação é Grupta (1996) que coloca que, embora a produção enxuta e a agilidade já sejam utilizadas juntas, elas não caracterizam necessariamente a mesma função. Para ele, a produção enxuta implica em ser altamente eficiente em custo e produtividade, embora não necessariamente induza a ter alto poder de resposta às mudanças, conforme a agilidade. Atualmente a interação entre estes dois conceitos é uma das maiores forças e desafios, segundo Booth (1996). Booth e Hammer (1995) apontam diferenças entre os conceitos, nas quais se pode notar que:

- produção enxuta é tida por muitos como o simples aumento dos métodos de produção em massa, enquanto a manufatura ágil implica na quebra do molde de produção em massa a passa trabalhar com produtos muito mais customizados, que o cliente os demanda em quantidades quaisquer;

- $\quad$ agilidade embute no gerenciamento de manufaturas, conceitos de rápida formação de alianças ou companhia virtual, funções tipicamente ligadas à capacidade de introdução de novos produtos no mercado, enquanto a produção enxuta tende a ter funções no sentido de incremento de produtividade e de eficiência em custos, tipicamente produtivas. 
Goldman (1994) por sua vez define um padrão da evolução da competição baseada na produção em massa para a competitividade direcionada segundo os princípios da manufatura ágil (figura 2).

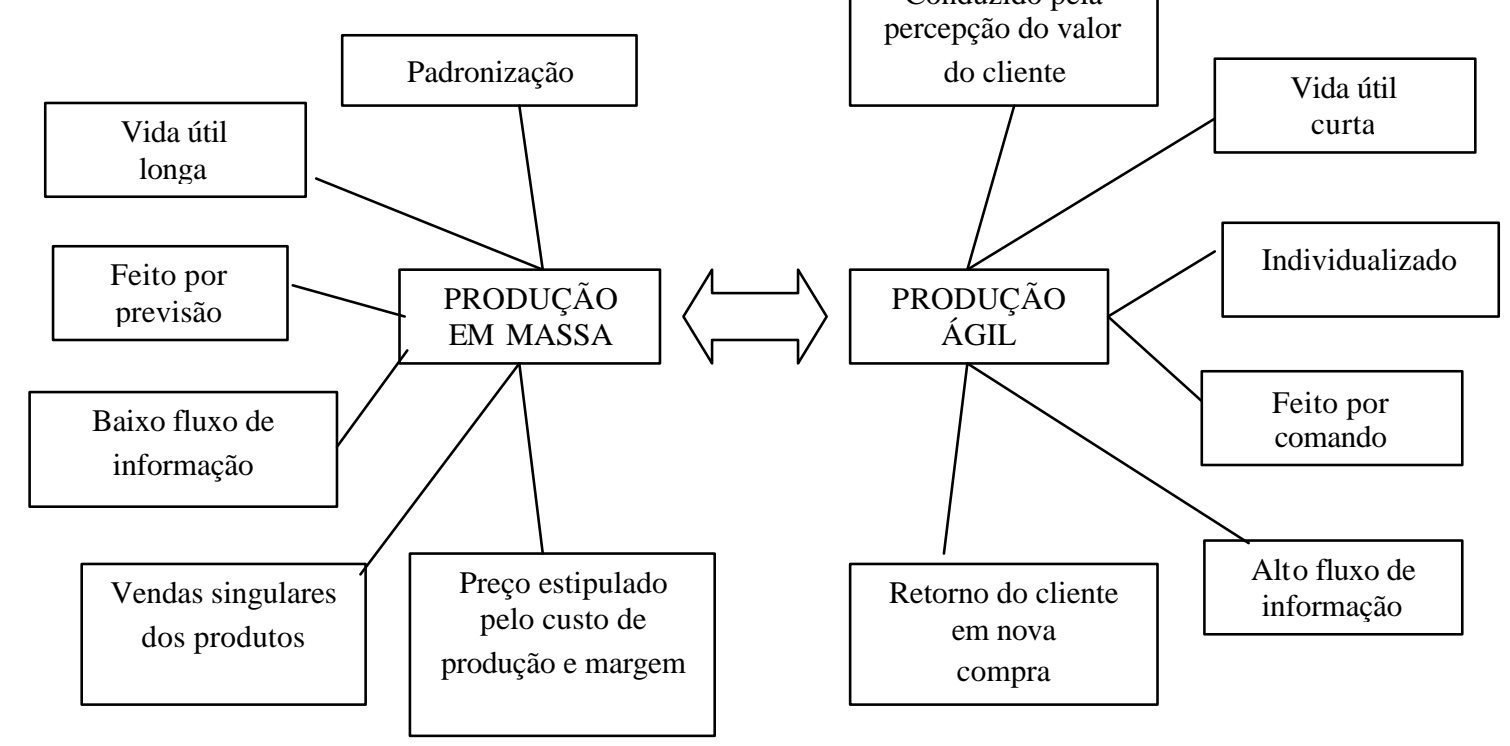

Figura 2 - Evolução para a agilidade (Irani, Sharp e Desai, 1999)

No esquema podem ser notadas as mais diferentes características entre as duas eras produtivas.

$\mathrm{Na}$ produção em massa a produção é padronizada, gerando poucas opções produtivas, feitos por demanda, sem que se haja uma previsão ou estudo prévio. Tem vida útil duradoura, o que denota vendas singulares e distantes. Trabalha com baixo fluxo de informação, o que dificulta a integração entre as partes da empresa, com o preço estipulado.

Na manufatura ágil a produção é altamente especializada, individualizada, feita por comando, isto é, produzida conforme estipulações feitas a partir de profundo acompanhamento do mercado. Tem vida útil visando à contínua troca de produtos, estabelecendo um vínculo com o cliente, tendo a intenção de fazer o cliente voltar a comprar produtos da empresa. Trabalha com alto fluxo de informação.

\subsection{Comparação entre as três eras produtivas}

Expressivas são as diferenças entre as três eras produtivas quando são comparadas algumas de suas características. Será conduzida neste item uma amostragem dessas 
características, em função de quadros estruturados por especialistas com a conseqüente interpretação destas informações.

O quadro 1 mostra diferenças propostas por Irani, Sharp e Desai (1999) entre produção em massa, a produção enxuta e a manufatura ágil. Para eles, esta diferença ocorre porque a segunda, originada no Japão não teria mobilidade suficiente para suportar os esforços decorrentes do ambiente competitivo de negócios.

No que diz respeito aos condutores que direcionam as eras, pode-se notar que a produção em massa tem características bastante práticas, não se atendo muito a previsões, por trabalhar com mercados estáveis, e ser fortemente orientado pela demanda. Já na produção enxuta, tem-se a mção de trabalhar com previsão, estando todo seu processo amplamente ligado à redução de desperdícios, operando com uma conduta direcionada à demanda prevista por acompanhamentos de mercado. A manufatura ágil, por sua vez, tende a enfocar com mais propriedade o cliente e, por ter características de alto poder de reconfiguração e operar em um mercado incerto, firma sua conduta na produção comandada, isto é, produz conforme estipulações feitas a partir de profundo acompanhamento do mercado.

Contudo, é interessante notar os autores especificam a preocupação com o cliente apenas no caso da manufatura ágil, opinião não compartilhada pelo pesquisador, em função das informações obtidas sobre a produção enxuta.

\begin{tabular}{|c|c|c|c|}
\hline & Produção em Massa & Produção Enxuta & Produção Ágil \\
\hline Condutores & $\begin{array}{l}\text { - Preço } \\
\text { - Economia de escalas } \\
\text { - Mercados estáveis } \\
\text { - Guiado pela demanda }\end{array}$ & $\begin{array}{l}\text { - Mercado } \\
\text { - Economia de desperdício } \\
\text { - Mercados previsíveis } \\
\text { - Feito por previsão }\end{array}$ & $\begin{array}{l}\text { - Cliente } \\
\text { - Economia da } \\
\text { diversidade } \\
\text { - Mercados } \\
\text { imprevisíveis } \\
\text { - Feito por comando }\end{array}$ \\
\hline Foco & $\begin{array}{l}\text { - Equipamentos e } \\
\text { facilidades }\end{array}$ & - Tecnologia e sistemas & - Pessoal e informação \\
\hline Fornecedores & $\begin{array}{l}\text { - Muitos } \\
\text { - Baixo nível de confiança } \\
\text { - Relacionamento }\end{array}$ & $\begin{array}{l}\text { - Poucos } \\
\text { - Alto nível de confiança } \\
\text { - Cooperação }\end{array}$ & $\begin{array}{l}\text { - Seleção entre muitos } \\
\text { - Alto nível de confiança } \\
\text { - Risco dividido } \\
\text { /recompensa }\end{array}$ \\
\hline Organização & $\begin{array}{l}\text { - Divisão do trabalho } \\
\text { - Hierárquica }\end{array}$ & $\begin{array}{l}\text { - Formação de equipes } \\
\text { - Empresa horizontal }\end{array}$ & $\begin{array}{l}\text { - Habilidades múltiplas } \\
\text { - Empresa }\end{array}$ \\
\hline
\end{tabular}




\begin{tabular}{|l|l|l|l|}
\hline & & & $\begin{array}{l}\text { horizontal/vertical } \\
\text { - Energização }\end{array}$ \\
\hline Produto & - Poucas opções & & - Customizado \\
& - Qualidade inconsistente & - Grande qualidade & $\begin{array}{l}\text { - Projetado sob } \\
\text { propósito } \\
\text { - Grande qualidade }\end{array}$ \\
& & & - Adaptável \\
& & & - Baseado em \\
& & conhecimento \\
\hline Processo & - Rígido & - Autoxível & - Liderança \\
\hline
\end{tabular}

Quadro 1 - Diferenças chave (Irani, Sharp e Desai, 1999)

A diferença entre os focos também é bastante aparente, já que com a evolução dos métodos gerenciais, administrativos e produtivos, este enfoque também sofreu avanços, advindo de um enfoque estritamente prático por parte da produção em massa, passando pela formatação e acompanhamento de tecnologias e sistemas - produção enxuta e culminando na preocupação por parte da manufatura ágil para com sistemas de informação, tecnologia da informação e treinamento de pessoal.

Por se tratarem de eras produtivas subsequentes, muitas vezes suas características denotam o próprio caminho traçado pelos avanços estratégicos, tecnológicos e gerenciais ocorridos no decorrer do final do século 20.

Isto acontece quando é abordado, por exemplo, o relacionamento com fornecedores. $\mathrm{Na}$ era produtiva da produção em massa, o procedimento era o de agrupar inúmeros fornecedores, não possibilitando um acompanhamento dos seus procedimentos e ocasionando uma alta desconfiança por parte das empresas contratantes. Já com a produção enxuta, este quadro se reverte, que passa a trabalhar com poucos fornecedores, bem controlados e sob um sistema de cooperação mútua. E, novamente por se tratar de um conceito que trabalha com alto poder de reconfiguração, em função das variações de mercado, e por causa disso necessitar de um escopo de grande porte, a manufatura ágil volta a operar com muitos fornecedores, só que desta vez em regime de parceria, que passa a expor os fornecedores aos riscos mercadológicos inerentes.

A mesma situação do caso anterior acontece no que diz respeito à organização. $\mathrm{O}$ desenvolvimento das empresas começa com uma instituição hierarquizada, trabalhando segundo a especificação e comando predeterminados. Com o aumento da competitividade, a 
diminuição da fatia de mercado e a busca da vantagem competitiva, as empresas se horizontalizaram, formatando equipes de produção e delegando poderes e, mais ainda quando a situação de incerteza do mercado se potencializa, estas passam a necessitar de equipes com habilidades múltiplas, da energização de pessoal e da horizontalização e verticalização, trabalhando concomitantemente, abrindo frentes de trabalho e condensando as estratégias nos tomadores de decisão.

Também é o caso dos processos e produtos, na primeira eram altamente padronizados, evoluindo para procedimentos mais flexíveis e automatizados na produção enxuta, e por conseguinte, gerando mais opções de produtos, e culminado com a manufatura ágil, com processos adaptáveis e modulares.

No caso dos produtos da produção em massa, os autores os caracterizam com qualidade inconsistente. Sobre esta era industrial, o pesquisador teve alcance a informações que classificam apenas como um método produtivo por assim dizer "rústico", quando comparado aos métodos produtivos atuais. (Baker, 1996).

Finalmente, os autores classificam a filosofia da produção em massa como autoritária, sendo bem entendida com ressalvas, por entender o pesquisador que se trata de uma expressão um tanto forte para demonstrar a característica padronizada e inflexível desta era. A filosofia da produção enxuta é caracterizada como administrativa e por certo, este é um bom meio de classificá-la, e sendo a manufatura ágil caracterizada pela liderança. Liderança esta que é encontrada nos tomadores de decisão ágeis, que direcionam todo o processo produtivo, gerencial e administrativo.

Deve-se entender, contudo, que por se tratar de uma evolução, está implícita a idéia de que o avanço filosófico e conceitual não culmina no conceito de manufatura ágil. Este, por sua vez tende a ser apenas mais um capítulo importante neste processo de progressivas transformações filosóficas.

Nelson e Harvey (1995) mostram no quadro 2 outra comparação entre as três eras, agora se valendo de características mais palpáveis de empresas que operem segundo uma das três eras industriais, a produção em massa, a produção enxuta e a manufatura ágil.

De acordo com o que foi salientado para a interpretação do quadro 1, as características listadas neste quadro também traduzem a evolução ocorrida em função das mudanças de mercado, competitividade e enfoque conceitual.

Por se tratar de uma era produtiva que opera em mercados estáveis, com produção altamente manual os investimentos da produção em massa são habitualmente orientados a 
equipamentos e facilidades produtivas, enquanto que na produção enxuta o maior investimento é dado à tecnologia, operando com camadas produtivas removíveis e flexíveis no sentido de diminuir os desperdícios. Na manufatura ágil, investimentos são feitos para estabelecer sistemas de informação e treinamento de pessoal, possibilitando a formação de equipes multi-habilitadas, com alto poder de reconfiguração. Para tanto, como já foi mencionado, a empresa deve ter um porte grande para poder possibilitar estas mudanças.

\begin{tabular}{|c|c|c|}
\hline Produção em Massa & Produção Enxuta & Agilidade \\
\hline $\begin{array}{l}\text { - Investimento em } \\
\text { equipamentos e facilidades } \\
\text { - Trabalho altamente manual }\end{array}$ & $\begin{array}{l}\text { - Investimentos em tecnologia } \\
\text { - Camadas removíveis } \\
\text { - Redução do desperdício }\end{array}$ & $\begin{array}{l}\text { - Investimento em sistemas de } \\
\text { informação e pessoal } \\
\text { - Trabalho multihabilitado } \\
\text { - Grande porte, equipes } \\
\text { reconfiguráveis }\end{array}$ \\
\hline $\begin{array}{l}\text { - Pouca interação com o } \\
\text { trabalhador } \\
\text { - Muitas camadas }\end{array}$ & $\begin{array}{l}\text { - Interação com o trabalhador } \\
\text { - Formação de equipes }\end{array}$ & $\begin{array}{l}\text { - Parcerias em todos os } \\
\text { estágios de manufatura } \\
\text { - Equipes direcionáveis para o } \\
\text { trabalho, gerenciamento da } \\
\text { mudança }\end{array}$ \\
\hline $\begin{array}{l}\text { - Tempo de desenvolvimento } \\
\text { de produto em anos } \\
\text { - Qualidade inconsistente }\end{array}$ & $\begin{array}{l}\text { - Processo Estável } \\
\text { - Tempo de desenvolvimento } \\
\text { de produto em meses } \\
\text {-Alta qualidade no momento } \\
\text { da venda }\end{array}$ & $\begin{array}{l}\text { - Tempo de desenvolvimento } \\
\text { de produto em dias } \\
\text { - Alta qualidade durante toda } \\
\text { a vida útil do produto }\end{array}$ \\
\hline
\end{tabular}

Quadro 2 - Diferenças e relações conceituais entre as três eras industriais

(Nelson e Harvey, 1995)

Não é mencionado pelos autores, mas grandes investimentos também são feitos com a intenção de flexibilizar a cadeia produtiva, estabelecendo-a em módulos destacáveis (células isoladas), se assemelhando em muito das chamadas camadas removíveis da produção enxuta.

Em se tratando de pessoal, a produção em massa apresenta uma característica hierarquizada, estanque em pequenas camadas e com pouca interatividade entre camadas produtivas diferentes. Já a produção enxuta apresenta uma maior interação entre as camadas, denotando a formação de times especializados e integração horizontal. A manufatura ágil tem 
características bastante interativas, com alto fluxo de informação entre células diferentes, formação de parcerias dos times multi-habilitados, e ampla manutenção da previsão da mudança, ponto este que é muito influenciado por esta integração.

No que diz respeito ao desenvolvimento de produto, os autores salientam que as três eras produtivas diferem no tempo de desenvolvimento de projeto até a sua produção e na qualidade. Conforme já foi mencionado anteriormente, nenhum tipo de informação pertinente sobre a diferença na qualidade dos produtos produzidos segundo uma ou outra era industrial foi encontrado, que faz com que o pesquisador desconsidere este último item.

Importante é entender que esta três eras produtivas se desenvolvem atualmente lado a lado, em diferentes setores de diferentes indústrias. Contudo, estas foram criadas em épocas econômicas, políticas e sociais decorrentes, o que explica a proposição de que cada uma evoluiu da era anterior, respectivamente. No próximo item será abordada uma estrutura ágil, condicionante para uma empresa que queira trabalhar segundo o conceito de manufatura ágil.

\section{CONCLUSÃO}

As conclusões que podem ser tiradas deste processo são as seguintes:

- a revisão bibliográfica tenciona dar subsídios para que em um futuro, várias frentes diferentes de trabalho possam ser concebidas;

- A comparação entre as eras produtivas mostra que mesmo sendo eras conseqüentes, estas ainda são vistas trabalhando concomitantemente. A impressão que se pode ter deste processo de comparação é que as evoluções e progressos ocorridos em cada uma das eras incorre em melhorias significativas, e não obstante, quase sempre são mais sentidas nas novas técnicas e ferramentas gerenciais e administrativas, o que consolida a idéia de que muitos novos esforços ainda serão feitos neste sentido de evolução gerencial. Portanto, deve-se saber que este processo não culmina na manufatura ágil tal qual ela hoje se apresenta, e que muitos desenvolvimentos serão sentidos neste conceito, sendo estabelecidos ainda sob esta alcunha, ou com algum outro nome que sugira as idéias da época;

- por ser um conceito relativamente novo se percebe que mesmo existindo esforços por parte de especialistas e pesquisadores em todo o mundo, muitas áreas de pesquisa sobre a manufatura ágil ainda estão por aprofundar-se e necessitam desta discussão;

- no Brasil, o paradigma da manufatura ágil é pouquíssimo difundido, estando ainda incubado em poucos centros acadêmicos. No mundo, se tem conhecimento de que apenas vinte e sete empresas britânicas trabalham sob o gerenciamento ágil, mas este quadro se 
expande rapidamente. As pesquisas em território bretão são as mais avançadas do mundo. $\mathrm{O}$ aprofundamento e a cristalização dos conceitos envolvidos na manufatura ágil depende muito da troca de experiências e informações entre as diferentes frentes que trabalham com este assunto ao redor do mundo. Exatamente por isso que todas as informações deste trabalho serão repassadas a uma rede acadêmica mundial de estudo e aprofundamento sobre a manufatura ágil, dirigida pelo Professor Zahir Irani, PhD, da Brunel University, Londres;

- estudos mais aprofundados são necessários para o avanço da manufatura ágil. Pesquisas mais focalizadas e específicas poderiam contribuir para a solução dos maiores desafios do conceito. Investigações mais aprofundadas no agrupamento de métodos gerenciais, administrativos e produtivos que combinados aumentem a agilidade de uma empresa é ponto fundamental neste desenvolvimento;

- contudo, estudos devem ser feitos no sentido de se aumentar a agilidade sem burocratizar a empresa. Situação crítica para a manufatura ágil é a de desenvolver estudos com a intenção de evitar tal conseqüência; e

- em um futuro próximo a agilidade certamente virá a ser a vital estratégia para o sucesso e sobrevivência de uma companhia que opere no ambiente de negócios globalizado e incerto.

\section{BIBLIOGRAFIA}

BAKER, J., Agility and flexibility, what's the difference?, Working paper, The Cranfield School of Management, Inglaterra, 1996.

BOOTH, R. Agile Manufacturing, Engineering Management Journal, EUA, ano 6, v. 2, p. 105-112, 1996.

BOOTH, C., HAMMER, M., Agile Manufacturing: concepts and opportunities in ceramics, Ceramic Transactions, Yorkshire, Inglaterra, n. 50, p. 67-76, 1995.

BROOKE, L., Is agility the answer? Automotive Industries, Inglaterra, n. 234, v. 001, p. 101-116, 1993. 
BUNCE, P., GOULD. P. From Lean to Agile Manufacturing, IEE Colloquium (Digest), EUA, n. 278, p. 31-35, 1996.

BURGESS, T. F., Making the leap to agility: defining and achieving agile manufacturing through business process redesign and business network redesign. International Journal of Operations and Production Management. EUA, n. 14, v. 11, p. 23-34, 1994.

ClARK, K. B., FUJIMOTO, T., Product Development Performance: Strategy, Organisation, and Management at the World Auto Industry, Harvard University Publications, Working paper, Cambridge, EUA, 1991.

DAVIS, E., What is on America minds? Management Review, EUA, n. 398, p. 14-20, 1995.

DRUCKER, P.F., Comeback of the entrepreneur, Management Today, New York, EUA, 1968.

GERHANI, R. R., Time-based management of technology: A taxonomic integration of tactical strategic roles. International Journal of Operations and Production Management, EUA, n. 15, v. 2, p. 19-35, 1995.

GOLDMAN, S. L., An Agility Primer, Agility Report, Agile Manufacturing Enterprise Forum, New Lawderdale, EUA, p. 1-4, 1994.

GUNASEKARAN, A. Agile Manufacturing: a framework for research and development. International Journal of Production Economics. Liverpool, Inglaterra, n. 62, p. 87-105, 1999.

GUNASEKARAN, A., Agile Manufacturing: The $21^{\text {st }}$ Century Competitive Strategy. Department of Management, ed. Charlton College of Business, University of Massachusetts, North Dartmouth, 2001, 820 p.

GUNASEKARAN, A., YUSUF, Y. Y, SARHADI, M., Agile manufacturing: The drivers, concepts and attributes. International Journal of Production Economics, Liverpool, Inglaterra, n. 62, p. 33-43, 1999. 
GRUPTA, U. G., MITTAL, R. O., Quality, time, and innovation based performance measurement system for agile manufacturing, Proceedings - Annual Meeting of the Decision Sciences Institute, EUA, v. 3, p. 1511-1513, 1996.

HAYEN, G. J. J. M., Change, challenge and continuity: An entrepreneurial vision of an electronics multinational, International Journal of Technology Management, n. 3, p. 3-17, 1988.

HAYES, R. H., PISANO, G. P., Beyond World Class: The new manufacturing strategy, Harvard Business Review, EUA, n. 345, p. 77-86, 1994.

IACCOCA INSTITUTE, 21 ${ }^{\text {st }}$ Century Manufacturing Enterprise Strategy, Lehigh University, Bethlehen, EUA, vol. 1, 1991.

IACCOCA INSTITUTE, 21 ${ }^{\text {st }}$ Century Manufacturing Enterprise Strategy, Lehigh University, Bethlehen, EUA, vol. 2, 1991.

IRANI, Z., SHARP, J. M., DESAI, S., Working towards agile manufacturing in the UK industry, International Journal of Produc tion Economics, Liverpool, Inglaterra, n. 62, p. 155$169,1999$.

JAMESMOORE, S.M.R. Agility is easy, but effective agile manufacturing is not, IEE Colloquium (Digest), EUA, n. 179, v.4, p. 234-247, 1996.

KIDD, P. T., Agile Manufacturing: Forging New Frontiers. Nova Iorque: ed. Addison Wesley Longman, 1994, 388 p.

KIDD, P. T., Agile Manufacturing: A strategy for the $21^{\text {st }}$ Century, IEE Colloquium Digest, EUA, n. 96/071, Março de 1996.

LINDBERG, P., Strategic manufacturing management: a proactive approach._International Journal of Operations and Production Management, EUA, n 10, v. 2, p. 94-106, 1990. 
NELSON, A., HARVEY, F. A., Technologies for training and supporting your agile workforce in Creating the Agile Organisations: Models, Metrics and Pilots. Proceedings $4^{\text {th }}$ Agility Forum Annual Conference. Agility Forum, Bethlehem, EUA, 1995.

PLOSSL, G. W., Production and Inventory Control: Principles and Techniques. 2nd ed. Prentice hall, Englewwod Cliffs, NJ, 1997.

SHARIFI, H., ZHANG, D. Z., A methodology for achieving agility in manufacturing organisations: An introduction. International Journal of Production Economics, Liverpool, Inglaterra, n. 62, p. 7-22, 1999.

THOMPSON, J., Organisation in Action, New York: McGraw-Hill, 1967.

YOUSSEF, M. A., Agile manufacturing: A necessary condition for competing in global markets, Industrial Engineering, EUA, p. ) 18-20, December 1992. 